Conceptual change challenges in medicine during professional development

\author{
Södervik, llona
}

2019-09

Södervik , I , Mikkilä-Erdmann , M \& Chi , M T H 2019 , ' Conceptual change challenges in medicine during professional development ' , International Journal of Educational Research , vol. 98 , pp. 159-170 . https://doi.org/10.1016/j.ijer.2019.07.003

http://hdl.handle.net/10138/334389

https://doi.org/10.1016/j.ijer.2019.07.003

cc_by_nc_nd

acceptedVersion

Downloaded from Helda, University of Helsinki institutional repository.

This is an electronic reprint of the original article.

This reprint may differ from the original in pagination and typographic detail.

Please cite the original version. 


\title{
Conceptual change challenges in medicine during professional development
}

\section{Södervik, I., Mikkilä-Erdmann, M. \& Chi, M.}

\begin{abstract}
This study investigates professional development during medical studies from a conceptual change perspective. Medical students' conceptual understanding and clinical reasoning concerning the central cardiovascular system were investigated during the first three years of study. Professional development was inspected from the perspectives of biomedical knowledge, clinical knowledge and skills needed to solve a patient case. Biomedical misconceptions regarding false beliefs and mental models were detected. Students with misconceptions were more likely to give lower level answers in clinical application tasks and to make inaccurate diagnoses compared to those students who had accurate conceptual understanding. Based on the results, pedagogical suggestions are discussed.
\end{abstract}

Keywords: professional development; misconception; conceptual change; medical education; higher education

Highlights

- Differences in biomedical and clinical knowledge among medical students exist

- False beliefs and mental model misconceptions among students were detected

- Instruction supported belief revision but not mental model transformation

- Quality of biomedical knowledge was related to success in clinical tasks 


\section{The Role of Prior Knowledge in Learning}

Over the past decade, research has conclusively shown that students come to science lessons loaded with expectations, previous knowledge and prior conceptions that in some cases significantly contradict the scientific view (Broughton, Sinatra, \& Nussbaum, 2013; Carey, 1985; Chinn \& Brewer, 1993; Diakidoy, Kendeou, \& Ioannides, 2003; Duit \& Treagust, 2003; Limón, 2001; Mason, 2001; Södervik, Vilppu, Österholm, \& Mikkilä-Erdmann, 2017; Vosniadou, 1994; 2013; Vosniadou \& Skopeliti, 2005). Currently, learning researchers agree that the main barrier to learning is often not what the student's knowledge structures lack, but what the student has, namely, alternative conceptual frameworks for understanding the particular phenomenon to be studied (Carey, 2000).

To reach a scientific understanding at university often means reorganising one's existing knowledge structures and sometimes even abandoning certain existing conceptions - a process that usually happens gradually and suggests intentional learning and teaching (e.g., Sinatra \& Pintrich, 2003). This kind of learning is described using the theories of conceptual change (see Limón \& Mason, 2002; Posner, Strike, Hewson, \& Gertzog, 1982; Vosniadou, 1994). There has been only few studies considering the need of conceptual change type of learning during professional development in higher education (see however, Boshuizen \& Schmidt, 2008; Flaig et al., 2018). Nevertheless, increasing evidence exists that conceptual learning of complex contents poses serious challenges not only for children but also for university students (e.g., Södervik et al., 2017).

When investigating conceptual understanding related to professional development, a domainspecific perspective is needed. It is well established that for expertise to be achieved, the kinds of conceptual changes necessary are often fundamentally different for different domains and even subdomains, and knowledge and the associated skills to use that knowledge develop simultaneously and interdependently (Boshuizen \& Schmidt, 2008; Treagust \& Duit, 2008). However, there is very little research related to discipline-specific development of expertise that identifies those domain-specific challenges of learning. Thus, in this paper, we focus on a cornerstone of professional expertise namely the domain-specific conceptual understanding from a conceptual change research perspective 
- and illustrate this in the medical context related to one of the most central content areas, the central cardiovascular system (CCVS).

During the school years, the CCVS is studied several times from elementary school to high school, and it is also one of the first topics covered in medical education at the university level. Understanding of this content requires learning a great number of individual concepts as well as their interrelations. For example, the heart is composed of a large myocardial muscle and four chambers building up the structural properties of the organ. However, one also needs to understand how the structure of the human heart, consisting of a muscle, relates to its function of pumping blood. Further, one must know how the structure relates to the behaviour in the human body and how behaviour relates to the function. These questions are related to biomedical knowledge (e.g., anatomy and physiology), which is typically studied in a 2.5 -year preclinical phase of medical studies.

\section{Biomedical knowledge and clinical reasoning in medical education}

In recent decades, several studies have aimed to understand how medical students acquire a high level of competence on their way from novices to intermediates and finally to becoming medical experts (e.g., Kuipers \& Kassirer, 1984; Schmidt \& Boshuizen, 1993; Schmidt \& Rikers, 2007). There is a general consensus that basic science or biomedical knowledge provides a foundation for clinical knowledge (Kaufman, Keselman, \& Patel, 2008; Woods, 2007), and recent studies have shown that students with better biomedical knowledge succeed better in clinical reasoning tasks (e.g., Södervik et al., 2017).

Different theories have been developed concerning how medical students construct a coherent understanding of biomedical and clinical knowledge during their studies, thereby gradually learning to solve complex clinical problems (e.g., Boshuizen \& Schmidt, 1992; de Bruin, Schmidt, \& Rikers, 2005; Feltovich \& Barrows, 1984; Kuipers \& Kassirer, 1984; Patel, Evans, \& Groen, 1989; Schmidt \& Boshuizen, 1993). Patel et al. (1989) argued that biomedical knowledge and clinical knowledge can be considered worlds apart, meaning that clinical knowledge and biomedical concepts construct separate knowledge structures; hence, biomedical knowledge is involved in clinical reasoning only in the sense that it provides coherence when solving exceptionally complex patient cases. However, 
currently, there is more empirical evidence supporting another perspective, wherein biomedical and clinical knowledge need to be integrated (i.e., encapsulated) for medical expertise to be achieved (Boshuizen, van de Wiel, \& Schmidt, 2012).

According to this current understanding, the development of expertise requires processes at different levels: conceptual understanding together with conceptual change, knowledge integration and learning the links between theoretical knowledge and practice (Boshuizen \& Schmidt, 2008). In the preclinical phase, which takes approximately the first 2.5 years of medical studies, the students' main aim is to build an extensive understanding of basic scientific knowledge, such as the anatomy and physiology of the human body. However, previous research has shown that the learning of biomedical contents poses challenges for medical students and often suggests the abandoning of certain misconceptions (e.g., Södervik et al., 2017). Later, during the clinical phase, biomedical knowledge needs to be integrated or encapsulated with clinical knowledge (understanding of so-called clinical applications; e.g., dysfunction of valves in veins causes the syndrome varicose veins when the blood is not able to return to the heart normally). Thus, successful professional development during medical education allow biomedical knowledge to become constructed into knowledge structures that comprise concepts under which many lower-level details and interrelations of information are organised (see Schmidt \& Boshuizen, 1993; Schmidt \& Rikers, 2007; Van de Wiel, Boshuizen, \& Schmidt, 2000). Hence, by successfully navigating these processes, students gradually learn to solve complex clinical patient cases effectively and accurately, a skill that requires integration of theoretical knowledge and practical skills. However, both learning researchers, who have studied learning in the medical context (e.g., Södervik et al., 2017), as well as medical educators (e.g., Badenhorst, Mamede, Hartman, \& Schmidt, 2015) know that these processes pose more challenges for some medical students than for others. We argue that to a great extent this is because of misconceptions and consecutive conceptual change challenges that many students struggle with during professional development (see also Coulson, Feltovich, \& Spiro, 1989). 


\section{Misconceptions with Different Dynamics as a Hinderance for Learning}

According to Chi (2008), knowledge can be misconceived at three levels of complexity, including false beliefs, mental models, and ontological categories (Chi, 2008). The most basic level of misconception ${ }^{1}$ is the false belief, which is a single incorrect idea that can usually be stated in a single proposition (Chi, 2013). False beliefs concern factual-level misconceptions. When knowledge is misconceived at the false-belief level, students have one or more incorrect individual beliefs about certain content that they are about to learn. For example, if a student thinks that all blood vessels have valves, this is in direct contradiction to the correct proposition that only veins have valves. False beliefs are thought to be relatively easy to rectify because they do not require radical restructuring of a mental model but rather a belief revision (Chi, 2008).

The next level of misconceptions according to Chi (2008) is that of flawed mental models. A mental model is a representation constructed by a learner that allows him or her to make inferences and reason qualitatively about a process or system (Gentner \& Stevens, 1983; Johnson-Laird, 1983). It has a similar relation structure to that of the phenomenon it represents and is often described as an analogue representation (see also, Spiro, Feltovich, Coulson, \& Anderson, 1989). It consists of multiple propositions and features as well as interrelationships between those features. Some of these relations are not represented explicitly as propositions and may be inferred from the features of the model. Thus, mental models are not simply a collection of individual beliefs, but because they possess complex interrelationships between propositions, they have a cohesive integrated structure (Chi, 2013). Because of this, even though a student may possess several correct individual beliefs about a scientific phenomenon, he or she may still have a flawed mental model. For example, about half of the eighth grade students in Chi's (2013) study had an initial single-loop model of the human

\footnotetext{
${ }^{1}$ These misinterpretations can be called misconceptions, misconceived prior knowledge, naïve beliefs, alternative conceptions, alternative beliefs, naïve conceptions or misinformation, depending for example on the perspective and underlying assumptions about cognition and learning (e.g., Driver, 1989; Hewson, 1982; Scott, Dyson, \& Gater, 1987). Although being aware that the term misconception is arguable (for example, because learning of science phenomena is a gradual process and certain naïve conceptions can be considered important transitional periods towards a better scientific understanding), in this paper we use this term and define it as a conception that is not in unison with current scientific understanding.
} 
circulatory system. According to this flawed model, blood goes to the heart to be oxygenated, then it is pumped to the rest of the body and after that back to the heart (in contrast, the correct double-pump model has two paths, with systemic and pulmonary circulations working simultaneously). Conceptual change at the level of mental models can be called mental model transformation.

The third and most complex level of misconceived prior knowledge according to Chi (2008) is the ontological level, where conceptual change requires a category shift. Misconceptions at this level occur when students misattribute a scientific phenomenon to one kind of category versus another (Chi, 1997; 2005). This means that if students' prior conceptions belong to one branch of ontological category and correct conceptions belong to another branch, they conflict by definition of kind or ontology, and therefore conceptual change requires a shift across ontological categories. Chi (2005) defined two broad ontological categories for scientific processes: direct and emergent processes. Direct processes are those in which the components of a system directly cause changes in other aspects/components of the system. The circulatory system is a good example of such direct processes, where the organisation of different parts (e.g., two loops of blood flow, one between the heart and the body and the other between the heart and lungs) dictates how the blood flows in the system (Chi, 2012). In emergent processes, instead, the system level activity emerges from the interaction of many different components acting simultaneously and cannot be attributed to direct causal effects of any one component or part (e.g., diffusion).

\section{Research Questions}

In order to investigate the professional development of medical students from novices towards intermediates, we synthesise data from studies conducted in Finland among one cohort of medical students ${ }^{2}$ and ask: 1 . How accurate are medical students' representations related to the CCVS, and how do students' representations change during the first two study years? and 2. How many students have misconceptions (false beliefs, mental model misconceptions or ontological misconceptions) of the scientific model concerning the CCVS at different measurement points during the first two study years? Lastly, we inspect the relationship between biomedical misconceptions and clinical reasoning

\footnotetext{
${ }^{2}$ Results related to the data of this paper are published also in Ahopelto et al. (2011) and Södervik et al. (2017).
} 
by asking: 3. How is success in biomedical assignments related to one's ability to solve a clinical application task, operationalised by one open-ended task concerning varicose veins and oedema? and

4. Is there a difference in performance on a later patient case task (concerning pulmonic embolus) measuring clinical skills between those who had and who did not have content-related biomedical misconceptions?

\section{Methods}

\section{Design}

The research design is presented in Table 1. Students' conceptual understanding related to the biomedical knowledge of CCVS was measured three times during first two study years. In Study Year 1, a baseline measurement, with a biomedical task was accomplished at the beginning of a cardiovascular course as part of the teaching session. The first follow-up, with the very same biomedical task, was accomplished after this cardiovascular course. In Study Year 2, the second follow-up data were collected in the second semester, and in addition to biomedical tasks, there was one clinical application task suggesting clinical reasoning together with biomedical knowledge. In Study Year 3, there was a patient case task measuring participants' clinical reasoning skills. The patient case task suggested combining biomedical and clinical knowledge. All answers were given in written (paper and pencil) form.

Table 1 The Research Design

\begin{tabular}{|c|c|c|c|c|}
\hline $\begin{array}{l}\text { Baseline in } \\
\text { Study Year } 1 \\
(N=119)\end{array}$ & & $\begin{array}{l}\text { First follow up in } \\
\text { Study Year } 1 \\
(N=119)\end{array}$ & $\begin{array}{l}\text { Second follow up in } \\
\text { Study Year } 2 \\
(N=119)\end{array}$ & $\begin{array}{l}\text { Third follow up in } \\
\text { Study Year } 3 \\
(n=31)\end{array}$ \\
\hline $\begin{array}{l}\text { Background } \\
\text { information } \\
\text { Biomedical drawing }\end{array}$ & $\begin{array}{c}\text { 6-week } \\
\text { conventional } \\
\text { cardiovascular } \\
\text { course }\end{array}$ & $\begin{array}{l}\text { Biomedical drawing } \\
\text { task concerning the } \\
\text { cardiovascular } \\
\text { system }\end{array}$ & $\begin{array}{l}\text { Biomedical open- } \\
\text { ended task concerning } \\
\text { the cardiovascular } \\
\text { system }\end{array}$ & $\begin{array}{l}\text { Patient case text } \\
\text { concerning the } \\
\text { pulmonic embolism }\end{array}$ \\
\hline $\begin{array}{c}\text { cardiovascular } \\
\text { system }\end{array}$ & & $\begin{array}{l}\text { Two biomedical } \\
\text { multiple-choice } \\
\text { questions }\end{array}$ & $\begin{array}{l}\text { Biomedical figure task } \\
\text { concerning the } \\
\text { pulmonary circuit }\end{array}$ & \\
\hline $\begin{array}{l}\text { Two biomedical } \\
\text { multiple-choice } \\
\text { questions }\end{array}$ & & & $\begin{array}{l}\text { Clinical application } \\
\text { task concerning } \\
\text { varicose vein } \\
\text { syndrome and oedema }\end{array}$ & \\
\hline
\end{tabular}




\section{Participants}

A total of 119 medical students from one Finnish medical school participated in the first three study phases (baseline, first follow up and second follow up). At the beginning of the longitudinal study, the students were, on average, 23 years of age (year of birth: $M=1987, S D=2.45$ ). A little more than half of the participants were women $(n=68)$, and the rest $(n=51)$ were men. From these students, a total of 31 students (women $n=24$; men $n=7$ ) participated in the fourth study phase (third follow up). Participation in all study phases was voluntary and informed consent was obtained.

\section{Measurements}

Biomedical tasks. In the first year, students' representations of the CCVS were investigated before and after an authentic course. The study focused on investigating students' representations related to CCVS and on detecting the conceptual difficulties students have with the biomedical content of the anatomy and physiology of the human heart. The written assignment both at baseline and at the first follow-up was 'a) Draw the structure of the CCVS (the heart with the largest vessels). Name the structures. b) Explain how the blood flows in the structures you drew'. There were also two multiple-choice questions concerning the timing of the right and left ventricular contraction and the oxygen content of the blood flowing in the pulmonary veins:

1: 'the right ventricle of the heart contracts: a) before b) after c) at the same time as the left ventricle'

2. 'the pulmonary veins bring a) oxygen-rich blood from the lungs to the heart b) oxygenpoor blood from the heart to the lungs c) oxygen-rich blood from the heart to the lungs'. The purpose of these multiple-choice questions was to examine further if the students correctly understood the systemic function of the cardiovascular system. The tasks were designed based on previous studies in which typical conceptual problems in understanding the content of the CCVS were identified (e.g., Michael et al., 2002).

In the second biomedical follow up during Study Year 2, the students' representations of biomedical understanding concerning the CCVS were examined again with two written assignments 
in order to determine changes in the level of the students' biomedical understanding. First was a biomedical question: 'Explain the path of a red blood cell from the left ventricle back to the same place'. Second was a figure task concerning the pulmonary circuit. After accomplishing this task (so that the sequential figure task would not affect the preceding answers), students were given a scheme of the pulmonary circuit and were asked to add arrows between the anatomical structures to indicate how the blood flows in the lesser circulation. The students were instructed that the number of arrows symbolised the number of the vessels (e.g., from the right ventricle via two pulmonic arteries to the lungs [one per lung] and from there via four pulmonic veins [two per lung] to the left atrium). The students were asked to mark the arrows with either a broken line to indicate oxygen-poor blood or an unbroken line to indicate oxygen-rich blood.

Clinical tasks. In addition to the biomedical tasks, there were two clinical reasoning tasks both handling venous thrombosis (superficial vs. deep-vein) and hence, both requiring understanding of biomedical knowledge related to the CCVS. The clinical application task in the second follow-up study during Study Year 2 concerned superficial venous thrombosis (i.e., varicose veins and oedema in the legs). The questions were: '1a) Why does a patient with varicose veins often suffer from oedema in the legs? 1b) Explain the mechanism of oedema'. Varicose veins and oedema are a very typical and relevant clinical problem that young physicians confront in everyday health care, and hence, understanding the pathophysiology of it is essential for medical students already in their first study years. Adequate response for the task suggested using biomedical knowledge related to the CCVS in the clinical context because understanding the pathophysiology of this disease requires knowing about the dysfunction of valves in blood vessels (but not all vessels, as solely veins have valves). However, unlike the task in Year 3, the clinical application task did not yet require solving a patient case, since the students had not yet learned about patient encounters. 
In Study Year 3, a written patient case concerning deep vein thrombosis was used. This task ${ }^{3}$ (Appendix A) suggested combining biomedical knowledge with clinical reasoning skills. The topic, pulmonary embolus, was chosen based on the fact that it was known to be familiar to the students; further, knowledge of the pathophysiology underlying this condition suggests an understanding of the biomedical content related to the CCVS. The patient case text ( 225 words) was written to simulate the phases of a patient encounter in a healthcare centre. Therefore, the text followed a patient case, including anamnesis (i.e., medical history of the patient), status and examination results from laboratory tests. After reading the case, the participants were asked to make a diagnosis.

The text was semantically categorised into different levels, as follows: key sentences (including relevant and essential information for the diagnosis), supplementary sentences (which included neutral information but still supported the reader in excluding incorrect options) and irrelevant sentences (containing irrelevant information). The relevant sentences were structured to fit to a typical but not the most prototypical manifestation of the disease (e.g., Charlin, Boshuizen, Custers, \& Feltovich, 2007).

\section{Data Analysis}

Analysis of biomedical tasks. The data from the biomedical questions in both years were analysed qualitatively and then quantified. Firstly, an analysis tool was constructed, in which a total of six links in Year 1 (Appendix B) and eight links in Year 2 (Appendix C) connected the central concepts of the cardiovascular system.

The participants' representations were scored using the tool so that correct scientific conceptions were marked with green links, which increased the total score by 2 points. In order to achieve a green link (e.g., between the boxes of aorta and periphery), the name of the structure (aorta) and its function (carries blood from the left ventricle to the systemic circuit) needed to be correctly

\footnotetext{
${ }^{3}$ The patient case text was written by the first author and evaluated and commented on by two cardiology specialists (these experts also act as medical teachers having an understanding about the knowledge level of the third-year students) to guarantee the validity of the text content. After designing the text, it was piloted with six fourth-year medical students, and the readability of the text was improved regarding the comments received from the students.
} 
declared. Over-simplified or insufficient conceptions (e.g., the name of the structure was missing, but the function was correctly explained) were marked with yellow links, which increased the score by only 1 point. Incoherent conceptions (e.g., correct answer on the drawing task but wrong in the written explanation) were marked in brown, which decreased the score by 1 point, whereas clear misconceptions were marked with red links, which decreased the score by 2 points. The link was left unmarked if neither the name nor the function of the structure was mentioned at all, which resulted in 0 points. The biomedical scores were standardised in order to have a comparable maximum score of 12 points in Years 1 and 2.

Consistent analyses enabled a comparison of students' biomedical understanding between Study Years 1 and 2, although the biomedical tasks varied between the years. By using this kind of analysis method, it was possible both to understand the model that the student had constructed as well as to detect in which part of the system the possible misconceptions occurred. An inter-rater reliability analysis was accomplished with $20 \%$ of the data, and Cohen's kappa value of reliability was found to be 906 .

The analysis related to dynamics of misconceptions was conducted using a directed content analysis approach, in which codes of analysis are derived from theory before and during data analysis (Hsieh \& Shannon, 2005). Misconceptions were classified on the categories of false beliefs, misconceptions at the mental model level and misconceptions at the ontology level.

False beliefs were misconceptions related to for example names or the number of central structures of the CCVS such as central vessels or structures of the heart. In contrast, misconceptions preventing understanding the function of the system as a whole, such as single-loop or serial loops conceptions, were categorised as mental model-level misconceptions. Misconceptions at the level of ontology could not be detected. Examples of categories of different dynamics of misconceptions are presented in Figure 1. Frequencies of students with different levels of misconceptions or a scientific model at different time points were calculated. 
A

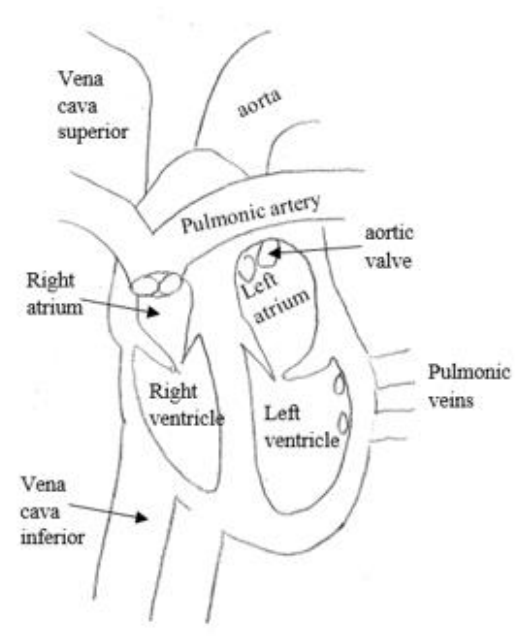

B

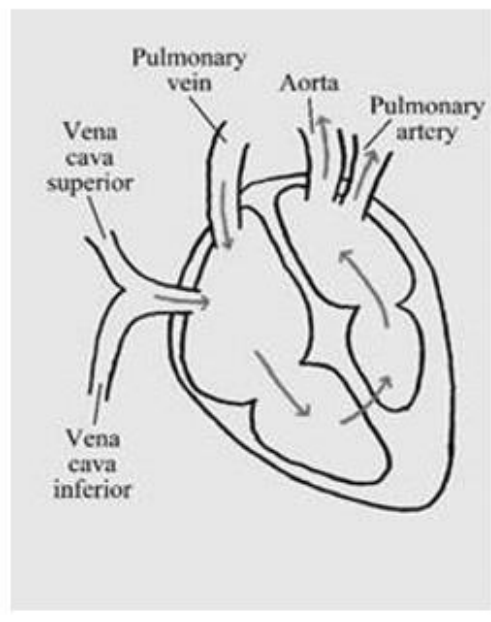

C

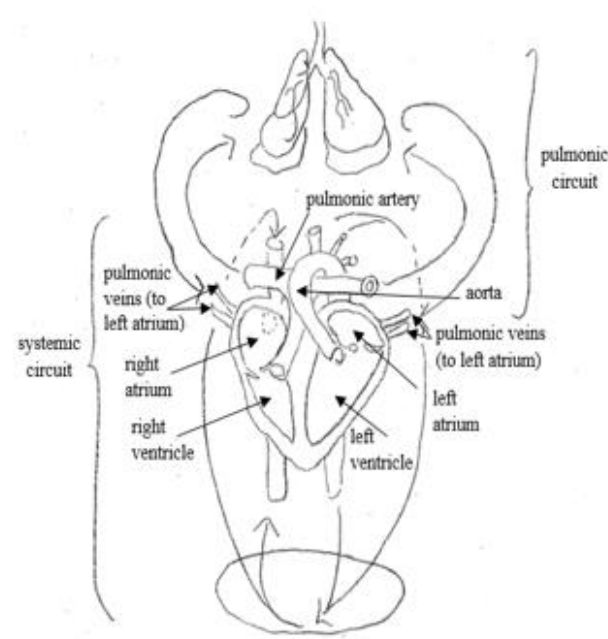

Figure 1. Drawings of the human heart and blood flow in it by first-year medical students as examples of (a) a false belief in which central veins have been misplaced i.e. mixed up between atria and ventricles, (b) mental model-level misconception with a single-loop idea and (c) a scientific model.

Analysis of clinical tasks. The answers for the clinical application task utilised in Study Year 2 were scored so that at least the following aspects had to be explained in order to gain the maximum score of 5: varicose veins are related to the dysfunction of valves in veins (1 point) when the blood is not able to return to the heart normally (1 point). Because of the hydrostatic pressure (1 point), the plasma starts to filter through the capillary to the surrounding tissues (1 point), causing oedema. Varicose veins are typical in the legs because of gravitation (1 point). Depending on the quality of the answer, 0.5 and 0.25 points were also given. Certain students explained parts of the mechanism even more closely, but that did not result in extra points. Thus, a perfect description of the mechanism of oedema was not required, because the students had only three semesters of medical education, and they had studied this content almost a year before. A typical answer to the clinical question did not include misconceptions, but was superficial and deficient, such as the answer of one student, which was scored as 2.75 points: 
In varicose veins the superficial veins are distended, because when the valves between deep and superficial veins fail the blood gathers to the superficial veins. That causes an oedema, because the pressure in those veins increases and thus, the plasma gets to the surrounding tissues.

In order to investigate, if biomedical knowledge developed differently between student groups with lowest, average and highest scores in clinical task, the students were divided into three groups according to their scores on the clinical task: weak ( $<1.75$ points), moderate $(2.00-3.25$ points $)$ and excellent (3.5-5.0 points).

The diagnoses made by the participants for the patient case text in Study Year 3 were categorised as either correct or missing/incorrect based on the rules outlined together with two medical experts. Missing and incorrect diagnoses were merged into one group because there was only one student who did not give a diagnosis at all.

Statistical analyses. Chi square $\left(\chi^{2}\right)$ tests, Pearson's correlation tests and one-way and repeated measures of ANOVAs were accomplished using SPSS Statistics 24 (IBM, Armonk, NY).

\section{Results}

The results of the longitudinal study showed that medical students' biomedical knowledge of the CCVS increased significantly (with a large effect size) during the first two study years $(F[2,236]$ $=20.11, p<.00, \eta^{2}=.146$; Figure 2). The result was expected, as the preclinical phase consists mainly of studying biomedical contents, and the CCVS is one of the main topics. 


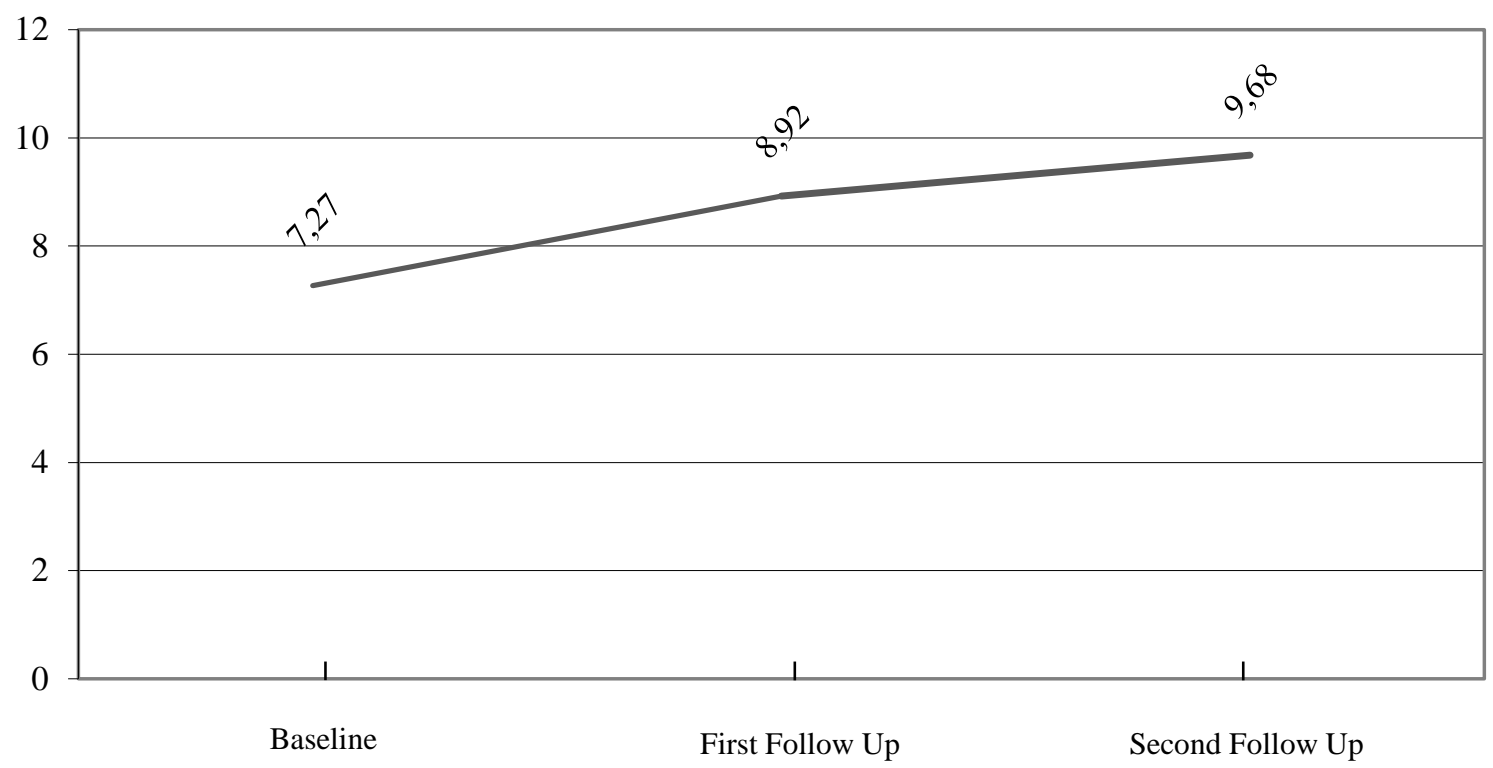

Figure 2. The scores of biomedical knowledge at different measurement points.

\section{Biomedical Misconceptions Among Medical Students in Study Years 1 and 2}

Next we investigated how many of the participants had false beliefs, mental model-level misconceptions or a scientific model at different measurement points (Table 2). It became apparent that in Year 1, half of the students $(n=61 / 119,51 \%)$ had misconception(s) before the course handling the CCVS. One-fifth of the participants (20\%) had false beliefs, such as wrong conceptions related to the number or names of central vessels. An even greater number of participants $(n=37,31 \%)$ had mental model misconceptions such as single-loop or serial loops conceptions. These mental modellevel misconceptions indicating that the student had erroneous understanding about the system as a whole, since these students did not understand the double-pump function of the heart, where the two ventricles of the heart pump blood to a lesser and systemic circuit in unison.

In the first measurement, approximately half (49\%) of the students had a scientific model, and the proportion increased to $62 \%$ in the first follow-up and $66 \%$ in the last measurement. Similarly, the number of students with mental model-level misconceptions decreased dramatically during the studies, and solely $3(3 \%)$ had them in the final measurement. However, the amount of false beliefs 
decreased as a result of the course in Study Year 1 but increased again from Year 1 to Year 2, being as high as $32 \%$ in the second follow-up measurement.

Table 2.

Frequencies of Students with Scientific Models or Misconceptions with Different Dynamics at Three Measurement Points $(N=119)$

\begin{tabular}{cccc}
\hline & $\begin{array}{c}\text { Baseline } \\
\text { (Study Year 1), } \\
\mathrm{N}(\%)\end{array}$ & $\begin{array}{c}\text { First Follow Up } \\
\text { (Study Year 1 After the Course) })\end{array}$ & $\begin{array}{c}\text { Second Follow Up } \\
\text { (Study Year 2), } \\
\mathrm{N}(\%)\end{array}$ \\
\hline False beliefs & $24(20)$ & $12(10)$ & $38(32)$ \\
$\begin{array}{c}\text { Mental model } \\
\text { misconceptions }\end{array}$ & $37(31)$ & $33(28)$ & $3(3)$ \\
$\begin{array}{c}\text { Scientific or almost } \\
\text { scientific model }\end{array}$ & $58(49)$ & $74(62)$ & $78(66)$ \\
\hline
\end{tabular}

When investigating the changes in misconceptions among the student group at different measurement points (Table 3), it became evident that 23 students (19\%) presented scientific models in each measurement. A total of 16 students (13\%), who started at baseline with false beliefs and a total of 26 students (22\%), who started at baseline with mental model misconceptions ended up having the correct scientific model. However, there were seven students $(6 \%)$ who presented scientific models in the baseline measurement but developed false beliefs or mental model misconceptions in the follow ups. 
Table 3. Cross Tabulation of Participants with Either Scientific Models or Different Level

Misconceptions at Different Measurement Points $(N=119)$

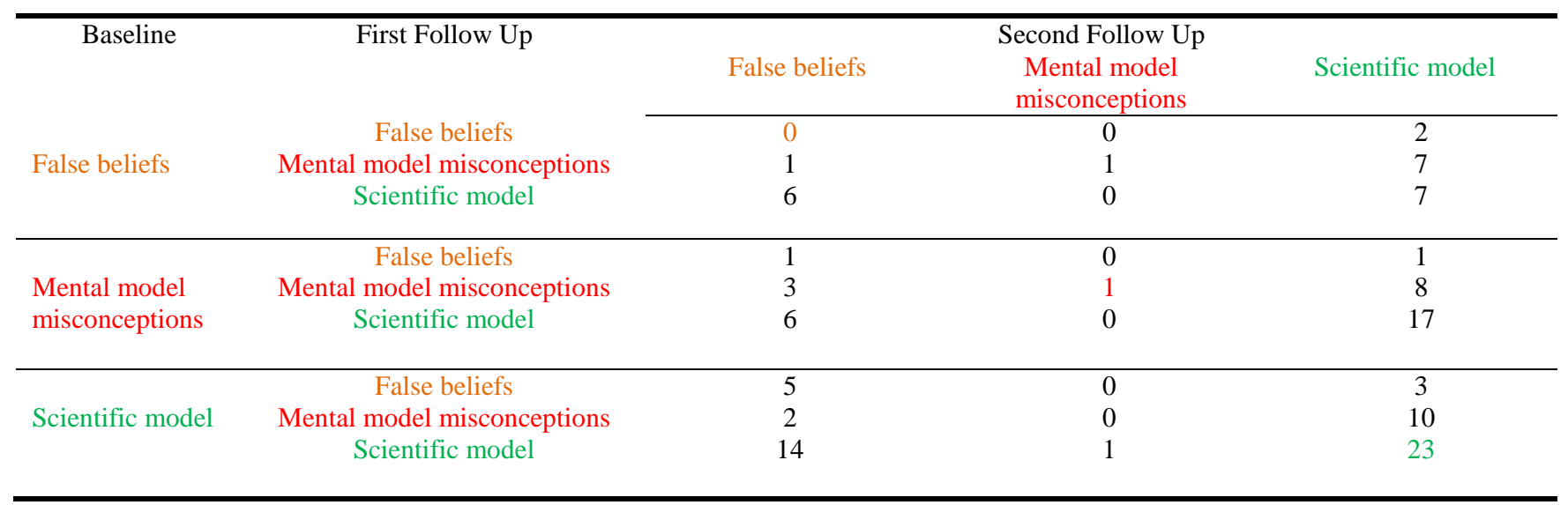

\section{Quality of Biomedical Knowledge and Misconceptions in Relation to Clinical Reasoning Skills}

In Study Year 2, the students received on average 2.47/5.00 points $(\mathrm{SD}=1.04, \mathrm{Min}=0.00$, Max $=4.75)$ on the clinical application task. It became apparent that scores from the biomedical task during the second follow up correlated with the scores from the clinical application task $(r=.319, p<$ .000). When comparing biomedical knowledge scores between the student groups of weak $(n=30)$, moderate $(n=62)$ and excellent $(n=27)$ based on the clinical application task scores, it became apparent that the difference between the biomedical scores was significant during the second follow up $\left(F[2,116]=5.13, p=.006, \eta^{2}=.084\right.$, medium effect size; Table 4). The results show that students, who gave the highest level answers in the clinical task had improved their level of biomedical knowledge most between the first and second study year $\left(\mathrm{F}(2,116)=3.86, p=.024, \eta^{2}=.036\right.$; Box's $\mathrm{M}=16.16, p=.02)$. 
Table 4.

The Scores of Biomedical Knowledge at Different Measurement Points in Relation to Success on the Clinical Application Task

\begin{tabular}{|c|c|c|c|c|c|c|}
\hline \multirow[t]{2}{*}{ Period } & \multirow[t]{2}{*}{ Clinical Task Category } & \multicolumn{5}{|c|}{ Biomedical Task Scores } \\
\hline & & $N$ & $M$ & $S D$ & Min & Max \\
\hline \multirow{2}{*}{ Baseline } & Weak & 30 & 6.43 & 4.70 & -6.00 & 12.00 \\
\hline & Excellent & 27 & 7.63 & 3.10 & 0.00 & 12.00 \\
\hline \multirow{2}{*}{$\begin{array}{c}\text { First Follow } \\
\text { Up }\end{array}$} & Weak & 30 & 8.50 & 3.18 & 0.00 & 12.00 \\
\hline & Moderate & 62 & 9.29 & 2.61 & 3.00 & 12.00 \\
\hline \multirow{3}{*}{$\begin{array}{c}\text { Second } \\
\text { Follow Up }\end{array}$} & Weak & 30 & 8.937 & 3.25 & 1.50 & 12.00 \\
\hline & Moderate & 62 & 9.47 & 2.43 & 2.25 & 12.00 \\
\hline & Excellent & 27 & 11.00 & 1.54 & 5.25 & 12.00 \\
\hline
\end{tabular}

Later, when investigating the results of the patient case task accomplished during Study Year 3 , it became apparent that less than half of the participants $(14 / 31,45 \%)$ made a correct diagnosis for the patient case. From that group of students, approximately half had had biomedical misconception(s) in previous study years $(16 / 31,52 \%)$. A total of $11 / 16(69 \%)$ of those students who had had biomedical misconception(s) in Years 1 and/or 2 were not able to diagnose the patient case correctly in Study Year 3. In contrast, solely 5/16 (31\%) of those with biomedical misconception(s) in preceding year(s) ended up with a correct diagnosis (Figure 3). Of those who had had a scientific model in the preclinical phase (no misconceptions in Study Years 1 and 2), 9/15 (60\%) made a correct diagnosis (Figure 3). 


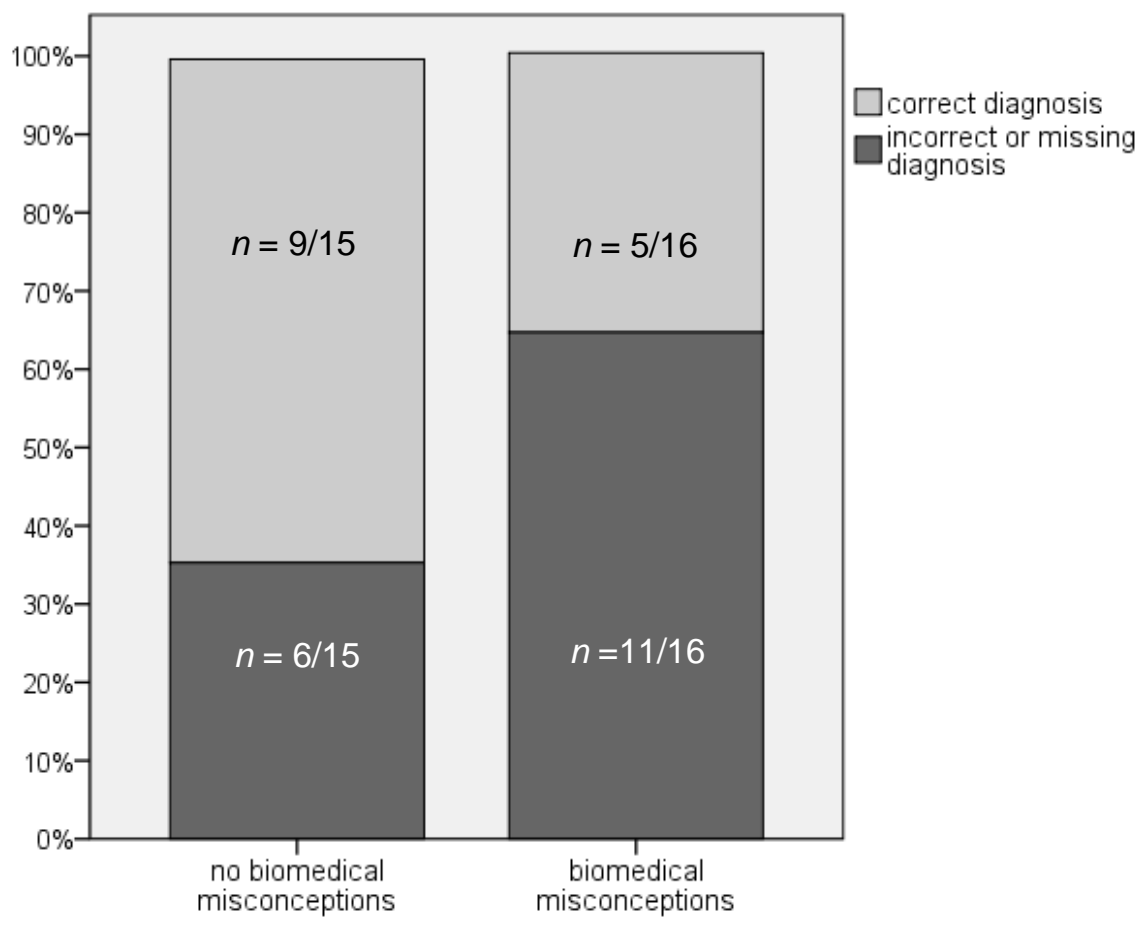

Figure 3. Comparison of students with and without biomedical misconceptions during the preclinical phase who had either correct or missing/incorrect diagnoses in the patient case task in Study Year 3.

\section{Discussion}

Our main interest in this article focused on investigating the development of biomedical knowledge concerning the CCVS from a conceptual change perspective generally and in relation to success on clinical tasks among medical students. Based on the previous research related to professional development in higher education (Gadgil, Nokes-Malach, \& Chi, 2012; Södervik et al., 2017), we hypothesised that a domain-specific conceptual change perspective would have an important role in explaining the development of expertise in medicine. In this study, we focused on one of the most central biomedical subjects, the CCVS, and investigated the development of biomedical knowledge and possible misconceptions related to it during the first years of medical studies. Furthermore, students' quality of biomedical knowledge was compared to their success in clinical tasks operationalised by two tasks suggesting the application of biomedical knowledge.

The results revealed that generally students' biomedical knowledge increased during the studies. This result was expected, as the preclinical phase consists mainly of studying biomedical 
contents, and the CCVS is one of the main topics. However, medical students, who are a highly selective group ${ }^{4}$, had biomedical misconceptions with different dynamics related to the CCVS. Onefifth of the first-year medical students had false beliefs (e.g., related to the number of vessels or to the names of structures), and nearly one-third had mental model misconceptions (so-called single-loop or serial loops conceptions) related to the content of the CCVS before entering a cardiovascular course.

The number of students with false beliefs halved from the baseline to the first follow up as a result of the cardiovascular course. However, when measuring students' biomedical knowledge related to the CCVS again in Study Year 2, the number of students with false beliefs had increased remarkably. Additionally, it seems that the group of students with false beliefs fluctuated between measurement points. Thus, according to the results of this study, it also seems that beliefs, both true and false, seem to be unstable by nature and therefore false beliefs are quite easily (re)developed. Based on the previous studies, belief revision is relatively easy to achieve because it does not require radical restructuring of knowledge (Chi, 2008) and can thus be learned relatively easily based solely on a surface level instruction without permanent restructuring of mental models.

In contrast, misconceptions preventing understanding of the system as a whole (i.e., mental model misconceptions) decreased only slightly during the course. Conceptual change (i.e., mental model transformation) related to this type of misconception requires radical restructuring of one's mental model and typically suggests intentional studying and teaching (Sinatra \& Pintrich, 2003). However, the medical curriculum is dense, the ideas are difficult and the pace is fast. Additionally, aspects of anatomy and physiology of the CCVS measured in this study can be called very basic knowledge that is studied several times during one's school years. As a result, medical teachers may be under the assumption that this content would be correctly understood by students already before entering the course or may expect that students study it independently to allow teachers to focus more on applied contents in their lectures. Additionally, most of the medical teachers are experts who themselves have reorganised their own knowledge structures many times but may no longer be aware

\footnotetext{
${ }^{4}$ In country removed for blind review purpose, approximately $12 \%$ of the applicants are accepted into medical school. Applicants (at data collection time) were selected based on a demanding entrance exam consisting mainly of open-ended questions measuring biomedical knowledge in biology, chemistry and physics.
} 
of problems concerning the learning of basic biomedical knowledge (see Boshuizen, Schmidt, Custers \& Van deWiel, 1995). All in all, it seems that in this case, the instruction in the cardiovascular course supported knowledge enrichment and belief revision instead of mental model transformation.

Both mental model misconceptions found in this study, single loop and serial loops, indicate challenges in understanding that there are two simultaneously acting paths in the circulatory system. Considering the misconception of serial loops, the students seemed to understand the double-pump function of the heart but considered the loops more or less separated from each other. In addition, a single-loop misconception also acts as evidence that the fundamental idea of the anatomy of a fourchambered heart and its relation to the physiology of the circulatory system in a human is poorly understood. The results are in line with several previous studies that have reported difficulties in learning the content of the CCVS and respiratory physiology among different aged learners (e.g., Chi, 2005; Coulson et al., 1989; Michael et al., 1999; Michael et al., 2002). However, only three students presented mental model misconceptions in the second year of studies indicating that later studies supported mental model transformation.

Challenges in understanding the relations between anatomy and physiology, found in this study, may also indicate ontological-level misconceptions due to the fact that anatomical structures (such as arteries, veins, valves etc.) belong to the ontological branch of objects, whereas physiological aspects (such as blood flow) belong to the ontological branch of (direct) processes. The effectiveness of the human circulatory system is due to a great extent to the anatomy of the heart (four chambers: upper right and left atria and lower right and left ventricles). The right and left sides of the heart are separated by a muscular wall - the atrioventricular septum - which prevents the mixing up of oxygenrich and oxygen-poor blood. This is a key reason for the effective oxygenating of organs (see however Figure 1B drawn by a first-year medical student where the arrow indicates crossing of this septum). Thus, anatomy is not solely about a structure, but a manifestation of adaptive evolution. However, for some reason, the connection between anatomy and physiology is not clear for all students. This result is in line with a previous study by Badenhorst et al. (2015), in which the authors interviewed medical teachers about students' typical misconceptions and challenges related to learning. 
Adequate understanding of the interplay between structures and function requires connecting aspects of these different ontological branches, suggesting so-called systemic understanding. Systemic understanding means that one can run a mental model to predict future states of a system or to explain the cause of a change in the state of a system (Kaufman et al., 2008; for mental models, see JohnsonLaird, 1983), a skill that is needed in understanding causal explanations between, for example, structures and processes.

Based on the findings of this study, the quality of biomedical knowledge seems to some extent be related to students' success in the clinical application task in later years because the scores from the last biomedical knowledge test correlated with the scores of the clinical application task. This supports the claim that there is a relationship between biomedical knowledge and clinical knowledge (Boshuizen et al., 2012). Additionally, present and previous misconceptions seemed to be related to diagnostic accuracy in the patient case task, although this relation was not significant, which may be due to the small sample size in the last measurement. All in all, the study indicates that there are differences among medical students in their clinical reasoning skills at the early stage of the clinical phase, and interestingly, more successful and less successful students differed slightly in terms of their amount of misconceptions concerning the CCVS in the preclinical phase, although the differences were not statistically significant.

\section{Limitations of the Study}

The following aspects need to be considered when generalising the results of this study. In this study, students' understanding of only one specific area of biomedical content was measured. The content of the CCVS was chosen because it is a complex phenomenon in medicine, for which comprehensive understanding requires learning a great number of separate concepts as well as constructing an elastic and flexible simulation-like representation of the whole system. However, the study was not controlled for whether some of the students had, for example, practical experience on the topics from attending rounds in their clinical studies. In addition, clinical reasoning was also measured with only two tasks, which is why further in-depth studies are needed in the future in order to examine if the results can be generalised to other medical domains. Furthermore, when considering the results of this study, it is important for the reader to acknowledge the unavoidable unreliability 
particularly related to the group comparisons, although we utilized a very commonly used quartile splitting in generating the groups. Lastly, the students who volunteered to participate in the final study phase represented average or better-succeeding students. Based on our previous studies with this same cohort, we know that the students who struggled most with their studies during the preclinical phase did not participate in the last study phase.

In addition, a repeated follow-up design influences participants' performance because the participants can learn to answer certain types of questions. Furthermore, repeating measures might result in so-called respondent fatigue, wherein the participants lose their interest towards the study, which again may affect their answers (e.g., Lavrakas, 2008). This is one reason why the sample size dropped dramatically from Years 2 to 3 . However, there was only one study phase during a school year, and the measures did not radically differ from the normal curriculum-based tests used in medical education.

Lastly, the biomedical tasks were tailored to measure students' understanding related to anatomy and physiology of the CCVS in factual and systemic levels. However, ontological misconceptions typically relate to more general assumptions or natural laws. Hence, it can be speculated that a requirement to explain, for example, the process of diffusion process in the lungs between oxygen and $\mathrm{CO}_{2}$ would have enabled detecting of ontological-level misconceptions.

\section{Pedagogical Contributions}

To develop systemic, expert level understanding takes time and requires many conceptual change transformations among novices. Most of these changes do not occur naturally but require systematic studying by students and support from the higher education learning environment. However, in this era of increasing complexity, there seems to be a gap between what we need our medical experts to do and the training we provide them (see also Mypoulos, Kulasegaram, \& Woods 2018).

It is paradoxical that although medical faculties have been one of the leading actors in the development of university pedagogy, the development of domain-specific pedagogy in medicine is still in its infancy. The problem is that medical teachers are often not aware of students' typical 
misconceptions, which hinder their learning, or teachers might not even necessarily consider instruction as an efficient way to support students' learning (see Michael, 2002; Michael et al., 1999).

One of the primary instructional techniques promoting conceptual change has been supporting students to become aware of their own thinking or metaconceptual awareness (see Vosniadou, 1994). Additionally, we suggest that both students' and their teachers' epistemology (Mason, 2002) at the domain-specific level play a role in the development of expertise. Personal epistemological beliefs (i.e., one's idea about the nature of knowledge and the nature of learning) play a role in learning and epistemological beliefs may facilitate or constrain it because these beliefs may or may not guide students to intentionally pursue the goal of conceptual change (Mason, 2002). However, often neither students nor their teachers are aware of the existence of misconceptions, how they affect individual learning processes and how they could be revised through instruction. Higher education teachers' own reasoning processes may also be so automatised that it is difficult for them to model their own expertlevel reasoning processes and to understand that new students enter their programmes with possible misconceptions.

One promising concrete approach facilitating conceptual change is prompting students to selfexplain their thinking. In previous studies, different self-explanation prompts have been shown to facilitate learning and transfer in a number of tasks, including learning of the circulatory system (Chi, 1997; 2000; Chi, Slotta, \& de Leeuw, 1994; Gadgil et al., 2012). Self-explanation is hypothesised to facilitate conceptual change because it forces students to reconcile their existing knowledge with the correct scientific knowledge, resulting in the acquisition of the correct beliefs through inference generation and knowledge revision (Gadgil et al., 2012). In addition, college students who were explicitly taught how to learn physics, such as building coherence, thinking in terms of mechanisms and considering implications of assumption, improved both students' epistemological expectations and also produced better pre-post gains (Redish \& Hammer, 2009). However, self-explanation protocols may preserve or even transmit or strengthen potential misconceptions if students operate without systematic feedback and consolidate their conceptions without questioning them. Thus, selfexplanation protocols that support students to critically consider their content-related procedural and 
epistemological conceptions by receiving feedback from their peers and instructors could facilitate conceptual changes in higher education.

\section{Conclusion}

This study highlights that different types and levels of conceptual changes are needed regarding medical expertise. These changes also seem to be inevitable for the development of clinical competence. Misconceptions in general are a serious problem for medical education because the systemic nature of the content means that a single misconception can have repercussions for the conceptions of many other interrelated aspects (see Chi, Chiu, \& deLeeuw, 1991; Coulson et al., 1989). Although this study is related to the medical domain, it contributes to the more general discussion about the role of conceptual change in understanding the development of expertise in higher education. Higher education teaching has a long history. Our current education models are oriented towards the acquisition and application of knowledge and must be expanded to include preparing students for new learning situations and evolving their knowledge for maintaining their expertise in a rapidly changing world (Lajoie \& Gube, 2018; Mypoulos et al., 2018). Based on the results of this study, conceptual change can inspire research in higher education and may be vital for understanding the acquisition of academic concepts in other domains besides medicine. 


\section{References}

Ahopelto, I., Mikkilä-Erdmann, M., Olkinuora, E., \& Kääpä, P. (2011). A follow-up study of medical studentsä biomedical understanding and clinical reasoning concerning the cardiovascular system. Advances in Health Sciences Education, 16, 655-668.

Badenhorst, E., Mamede, S., Hartman, N., \& Schmidt, H. G. (2015). Exploring lecturers' views of first-year health science students' misconceptions in biomedical domains. Advances in Health Sciences Education, 20, 403-420.

Boshuizen, H. P. A., \& Schmidt, H. G. (1992). On the role of biomedical knowledge in clinical reasoning by experts, intermediated and novices. Cognitive Science, 16, 153-184.

Boshuizen, H. P. A., \& Schmidt, H. G. (2008). The development of clinical reasoning expertise: Implications for teaching. In: J. Higgs, M. Jones, S. Loftus, \& N. Christensen (Eds.), Clinical reasoning in the health professions (3rd ed.). Oxford: Butterworth-Heinemann/Elsevier.

Boshuizen, H. P. A., Schmidt, H. G., Custers, E. J .F .M. \& Van de Wiel, M. W. (1995). Knowledge development and restructuring in the domain of medicine: the role of theory and practice. Learning and Instruction, 5, 269-289.

Boshuizen, H. P. A., van de Wiel, M. W. J., \& Schmidt, H. G. (2012). What and how advanced medical students learn from reasoning through multiple cases. Instructional Science, 40, 755768.

de Bruin, A. B. H., Schmidt H. G., \& Rikers, R. M. J. P. (2005). The role of basic science knowledge and clinical knowledge in diagnostic reasoning: A structural equation modelling approach. Academic Medicine, 80 (8), 765-773.

Broughton, S. E., Sinatra, G. M. \& Nussbaum E. M., (2013). "Pluto Has Been a Planet My Whole Life!" Emotions, Attitudes, and Conceptual Change in Elementary Students Learning about Pluto's Reclassification. Research in Science Education, 43 (2), 529-550.

Carey, S. (1985). Conceptual change in childhood. Cambridge, MA: MIT Press.

Carey, S. (2000). Science education as conceptual change. Journal of Applied Developmental Psychology, 2l(1), 13-19. 
Charlin, B., Boshuizen, H. P. A., Custers, E. J., \& Feltovich, P. J. (2007). Scripts and clinical reasoning. Medical Education, 41, 1178-1184.

Chi, M. T. H. (1992). Conceptual change within and across ontological categories: examples from learning and discovery in science. In R. Giere (Ed.), Cognitive models of science: Minnesota studies in the philosophy of science (pp. 129-186). Minneapolis, MN: University of Minnesota Press.

Chi, M. T. H. (1997). Quantifying qualitative analyses of verbal data: A practical guide. The Journal of the Learning Sciences, 6(3), 271-315.

Chi, M. T. H. (2000). Self-explaining expository texts: The dual processes of generating inferences and repairing mental models. In R. Glaser (Ed.), Advances in instructional psychology (pp. 161-238). Mahwah, NJ: Lawrence Erlbaum Associates.

Chi, M. T. H. (2005). Commonsense conceptions of emergent processes: Why some misconceptions are robust. Journal of the Learning Sciences, 14(2), 161-199.

Chi, M. T. H. (2008). Three types of conceptual change: Belief revision, mental model transformation, and categorical shift. In S. Vosniadou (Ed.), International handbook of research on conceptual change (pp. 61-82). New York: Routledge.

Chi, M. T. H. (2013). Two kinds and four sub-types of misconceived knowledge, ways to change it, and the learning outcomes. In S. Vosniadou (Ed.), International handbook of research on conceptual change (2nd ed., pp. 49-70). New York: Routledge.

Chi, M. T. H., Chiu, M.-H., \& deLeeuw, N. (1991). Learning in a non-physical science domain: The human circulatory system. Pittsburgh, PA: Pittsburgh University Learning Research and Development Center.

Chi, M. T. H., \& in, R. D. (2002). The process and challenges of conceptual change. In: M. Limón \& L. Mason (Eds.), Reconsidering conceptual change: Issues in theory and practice (pp. 3-27). Dordrecht, Netherlands: Kluwer Academic Publishers.

Chi, M. T. H, Roscoe, R. D., Slotta, J. D., Roy, M. \& Chase, C. C. (2012). Misconceived Causal Explanations for Emergent Processes. Cognitive Science, 36(1), 1-61. 
Chi, M. T. H., Slotta, J. D. \& de Leeuw, N. (1994). From things to processes: A theory of conceptual change for learning science concepts. Learning and Instruction, 4, 27-43.

Chinn, C. A. \& Brewer, W. F. (1993). The role of anomalous data in knowledge acquisition: a theoretical framework and implications for science instruction. Review of Educational Research, 63 (1), 1-49.

Coulson, R. L., Feltovich, P. J., \& Spiro, R. J. (1989). The nature of conceptual understanding in biomedicine: The deep structure of complex ideas and the development of misconceptions. In: D. A. Evans \& V. L. Patel (Eds.), Cognitive science in medicine: Biomedical modeling (pp. 113-172). Cambridge, MA: The MIT Press.

Diakidoy, I-A, N., Kendeou, P. \& Ioannides, C. (2003). Reading about energy: The effects of text structure in science learning and conceptual change. Contemporary Educational Psychology, $28,335-356$.

Driver, R. (1989). Students' conceptions and the learning of science. International Journal of Science Education, 11(5), 481-490.

Duit, R., \& Treagust, D. F. (2003). Conceptual change: A powerful framework for improving science teaching and learning. International Journal of Science Education, 25, 6, 671-688.

Feltovich, P. J., \& Barrows, H. S. (1984). Issues of generality in medical problem solving. In: H. G. Schmidt \& M.L. de Volder (Eds), Tutorials in Problem-Based Learning. Maastricht: Van Gorcum Assen.

Flaig, M., Simonsmeier, B. A., Mayer, A.-K., Rosman, T., Gorges, J., \& Schneider, M. (2018). Conceptual change and knowledge integration as learning processes in higher education: A latent transition analysis. Learning and Individual Differences, 62, 49-61.

Gadgil, S., Nokes-Malach, T. J., \& Chi, M. T. H. (2012). Effectiveness of holistic mental model confrontation in driving conceptual change. Learning and Instruction, 22(1), 47-61.

Gentner, D., \& Stevens, A. L. (1983). Mental models. Hillsdale, NJ: Lawrence Erlbaum Associates.

Hewson, P. W. (1982). A case study of conceptual change in special relativity: The influence of prior knowledge in learning. European Journal of Science Education, 4(1), 61-78. 
Hsieh, H.-F., \& Shannon, S. E. (2005). Three approaches to qualitative content analysis. Qualitative Health Research, 15(9), 1277-1288.

Johnson-Laird, P. N. (1983). Mental models. Cambridge, MA: Harvard University Press.

Kaufman, D. R., Keselman, A., \& Patel, V. L. (2008). Changing conceptions in medicine and health. In S. Vosniadou (Ed.), International handbook of research on conceptual change (pp. 295327). New York: Routledge.

Kuipers, B., \& Kassirer, J. P. (1984). Causal reasoning in medicine: Analysis of protocol. Cognitive Science, 8, 363-385.

Lajoie, S. P., \& Gube, M. (2018). Adaptive expertise in medical education: Accelerating learning trajectories by fostering self-regulated learning. Medical Teacher, 40(8), 809-812.

Lavrakas, P. J. (2008). Encyclopaedia of survey research methods. Accessed in April 2017, DOI: http://dx.doi.org/10.4135/9781412963947.

Limón, M. (2001). On the cognitive conflict as an instructional strategy for conceptual change: a critical appraisal. Learning and Instruction, 11, 357-380.

Limón, M., \& Mason, L. (2002). Prologue. In M. Limón \& L. Mason (Eds.), Reconsidering conceptual change: Issues in theory and practice (pp. $\mathrm{xv}-\mathrm{xx}$ ). Dordrecht, Netherlands: Kluwer Academic Publishers.

Mason, L. (2001). Responses to anomalous data and theory change. Learning and Instruction, 11 (6), 453-483.

Mason, L. (2002). Developing epistemological thinking to foster conceptual change in different domains. In M. Limón \& L. Mason (Eds.), Reconsidering conceptual change: Issues in theory and practice (pp. 301-335). Dordrecht, Netherlands: Kluwer Academic Publishers.

Michael, J. A., Richardson, D., Rovick, A., Modell, H., Bruce, D., Horwitz, B.,...Williams, S. (1999). Undergraduate students' misconceptions about respiratory physiology. Advances in Physiology Education, 277, 127-135.

Michael, J. A., Wenderoth, M. P., Modell, H. I., Cliff, W., Horwitz, B., McHale, P.,...Whitescarver, S. (2002). Undergraduates' understanding of cardiovascular phenomena. Advances in Physiology Education, 26, 72-84. 
Mypoulos, M., Kulasegaram, K., \& Woods, N. N. (2018). Developing the experts we need: Fostering adaptive expertise through education. Journal of Evaluation in Clinical Practice, 24(3), 674677.

Patel, V. L., Evans, D. A., \& Groen, G. J. (1989). Biomedical knowledge and clinical reasoning. In D. A. Evans, \& V. L. Patel (Eds.), Cognitive science in medicine: Biomedical modelling. Cambridge, MA: The MIT Press.

Posner, G. J., Strike, K. A., Hewson, P. W., \& Gertzog, W. A. (1982). Accommodation of a scientific conception: Toward a theory of conceptual change. Science Education, 66, 211-227.

Redish, E. F., \& Hammer, D. (2009). Reinventing college physics for biologists: Explicating an epistemological curriculum. American Journal of Physics, 77, 629-642.

Schmidt, H. G., \& Boshuizen, H. P. A. (1993). On acquiring expertise in medicine. Educational Psychology Review, 5(3), 205-221.

Schmidt, H. G., \& Rikers, R. M. J. P. (2007). How expertise develops in medicine: knowledge encapsulation and illness script formation. Medical Education, 41, 1133-1139.

Scott, P., Dyson, T., \& Gater, S. (1987). A constructivist view of learning and teaching in science. Leeds: University of Leeds.

Sinatra, G. M., \& Pintrich, P. R. (2003). Intentional conceptual change. Mahwah, NJ: Lawrence Erlbaum Associates, Inc.

Spiro, R. J., Feltovich, P. J., Coulson, R. L., \& Anderson, D. K. (1989). Multiple analogies for complex concepts: Antidotes for analogy-induced misconception in advanced knowledge acquisition. In S. Vosniadou \& A. Ortony (Eds.), Similarity and analogical reasoning (pp. 498-531). Cambridge, UK: Cambridge University Press.

Södervik, I., Vilppu, H., Österholm, E., \& Mikkilä-Erdmann, M. (2017). Medical studentsö biomedical and clinical knowledge: Combining longitudinal design, eye tracking and comparison with residents' performance. Learning and Instruction, 52, 139-147.

Treagust, D. T., \& Duit, R. (2008). Conceptual change: A discussion of theoretical, methodological and practical challenges for science education. Cultural Studies of Science Education, 3, $297-$ 328. 
Van de Wiel, M. W. J., Boshuizen, H. P. A., \& Schmidt, H. G. (2000). Knowledge restructuring in expertise development: Evidence from pathophysiological representations of clinical cases by students and physicians. European Journal of Cognitive Psychology, 12(3), 323-355.

Vosniadou, S. (1994). Capturing and modeling the process of conceptual change. Learning and Instruction, 4, 45-69.

Vosniadou, S. (2013). Conceptual change in learning and instruction - The Framework Theory Approach. In: S. Vosniadou (Ed.), International handbook of research on conceptual change : second edition (pp. 11-30). New York: Routledge.

Vosniadou, S. \& Skopeliti, I. (2005). Developmental shifts in children's categorization of the earth. In B. G. Bara, L. Barsalou \& M. Bucciarelli (Eds.), Proceedings of the XXVII Annual Conference of the Cognitive Science Society (pp. 2325-2330) Mahwah, NJ: Lawrence Erlbaum Associates.

Woods, N. N. (2007). Science is fundamental: The role of biomedical knowledge in clinical reasoning. Medical Education, 41, 1173-1177. 